\title{
The Business Model Discussion of Shopping Rebate Network
}

\author{
Chunpeng Li \\ School of Business and Information Technology \\ Quanzhou Normal University \\ Quanzhou, China \\ Chunpeng-li@163.com
}

\begin{abstract}
This article delve into the shopping rebate network business model from three aspects, including mode of operation, trends and profit model. Shopping rebate network build Taobao Open Platform B2C and third-party shopping guide website Affiliate rebate site. Users can go through the shopping rebate network Taobao e-commerce sites. Such as shopping, you can get cash rebates. As a new kind of online shopping patterns, it has the market value and development potential.
\end{abstract}

Keywords-online shopping rebate network; business model; cash rebates

\section{INTRODUCTION}

Shopping rebates businesses can stimulate sales, when a consumer buys goods or services, according to a certain percentage of business to the consumer to return cash or vouchers [1]. The shopping rebates can be seen as a special promotion, along with the development of the Internet. Traditional business models have to be ported to the top of the Internet. As early as 2000, this model appears in a foreign country and some of the larger rebate website as Ebates has been in operation for almost 10 years. At this point, after the network rebate, people are well-known gradually. And finally in 2006, the first rebate website www.51fanli.com came into being. In 2009, the Internet giant Tencent and Netease suddenly involved in the field, thus after rebate website attracted more and more attention.

\section{INTRODUCTION AND BACKGROUND OF A SHOPPING REBATE NETWORK}

\section{A. Shopping Rebate Networks}

Shopping rebate network in the form of cash back shopping gathered a large number of online shopping members, members from here to the major online shopping mall, after the completion of the order (no returns), the rebates network as a partner of the mall, from the mall to get a certain percentage of sales commissions, rebates network then commission the vast majority of the return to members, which is the source of the cash rebate [2]. In this mode, both gathered a large number of members for the site, but also for members to provide online shopping services to save money, more importantly, not only does not affect the interests of business, while they bring sales orders, is a threefold mode. December 2012 data, rebate network (51fanli) has 10 million registered members, to maintain more than 10 million monthly rebate amounts to attract more than 400 wellknown B2C electronic business Jingdong Mall, Dangdang, Shop No. 1 collective settled, cover $40 \%$ of the online shopping population.

\section{B. The Shopping Rebate Network of Background}

Shopping rebate network construction and operation is Internet-based open platform. Since 2007, Facebook opened up their platform which was a great success. In 2010, Taobao, Sina Weibo, Baidu, Shanda, Tencent have been trying to open part of the interconnected areas of API. Interface calls Taobao mass products and stores displayed on the site to get traffic from search engines. qq Taobao, Tencent qq, Sina microblogging account authorization the rebates network, eliminating the need for registered trouble.

(Business-to-Customer, marketing costs, business-tocustomer, an e-commerce model) website, such as Jingdong Mall, where customers Eslite, or seller Taobao Mall and fairs are facing increasingly high problems.CPScost per sale, ${ }^{4}$ The rebate network, as the connection network share groups with the seller of thirdparty platform, advertising model allows businesses to obtain new customers at a lower cost. Rebates stimulate the customers desire to buy; improve customer loyalty, which has a higher return on investment [3].

The rebate network of popular thanks to the online shopping market matures. People got used to the convenient and affordable online shopping experience. B2C At the same time, the rapid development of the B2C website has a professional website sales growing. People can choose all kinds of goods. Faced with such market conditions, people began to weary looking for more affordable trusted online shopping sites. b2c The rebate network model has a collection of a large number of highquality B2C businesses, eliminating the need for people to find the cost, while the return of cash to members. 


\section{Shopping REBATE NETWORK ClAsSificATION AND CHARACTERISTICS}

\section{A. Rebate Network Classification}

Rebate network as a new third-party shopping guide platform, recent years thousands rebates website where they stand, setting off a new round of rebates boom buy hot. The existing rebate website includes the following types:

1) Unity Taobao cash back site

Such as rice fold network, for example, rebates websites focus on Taobao rebates, great value Taobao and Taobao Mall online shopping market, B2C, C2C sellers, committed to get the highest percentage of rebates.

\section{2) Integrated cash back sites}

Such as: the return of net 51 rebates. 30300 Such sites advocate comprehensive rebate in cooperation with the online shopping platform Taobao, Dangdang, Jingdong Mall and other large and small, general merchants to cooperate in more than 30, like the back benefits up to more than 300 . To give customers rebates at the same time, provide more choices.

3) Parity rebate sites.

It is represented by such sites Netease cash back. Through data mining technology, mining the same product in different mall together, allowing users to parity various mall product price, quality of service, reputation in rebate. You can use the NetEase cash back so cooperation Mall, and solve repeatedly registration troubles.

4) Represented by the amount of such sites

Online store, supermarkets and other rebates hundred percent rebate of such sites is characterized by the rebate period longer every day in the back, but the daily rebate amount is only about two thousandths.

5) Taobao sun single rebate website

Such as 51 rebate, this type of site on the ordinary shopping rebates on the basis of increased sun single rebate. The user personally participate in the site's rebate, to share rebates mood and experience to obtain cash rebates site gift vouchers, promotions securities and so on.

\section{B. Different Types of Rebates Network Characteristics}

Comparing the above types of sites, it is not difficult to find the rebates site that has the following three characteristics:

Features 1, Collaboration with a number of wellknown businesses, such as: Taobao, Dangdang, Jingdong Mall. The number of large customer base of the business, help B2C mall publicity to promote their rebate website, but also with the big brands influence and standardized mode of operation.

Characteristics2, to meet the requirements of individual customers, parity nature rebates website must come to the fore. Users search for lower-priced goods, while also searched high degree of credibility, the praise more comprehensive product information.

Features3, whether it is the unity of the comprehensive rebate site, more and more emphasis on the user's social sharing. Marketing have all become good way of rebate site to improve user activity.

In increasingly competitive online sales, at the same time, we can see that the cooperation with such third-party shopping guide platform rebate network will gradually become the optimal choice of many B2C mall. Because the traditional network marketing, advertising spending generally accounts for $30 \%$ to $60 \%$ of the total expenditure of the online store, and publicity channels are relatively simple. Rebate site, on the one hand, businesses save part of the ad spending rebate website free publicity to help businesses; on the one hand, businesses will be part of the sales commission give rebates website. The website can not only be returned to the customer, but also enhance customer loyalty.

\section{Shopping Rebate Network Business Model ANALYSIS}

\section{A. Rebate Network Mode of Operation}

The rebate network as a third party, connect businesses and consumers, to bring shopping offers rebates for consumers, for businesses bring order and customer. B2C The rebate network mode of operation is very simple. The way is through an open platform, website advertising alliances, and independent third-party shopping guide platform with integrated electronic business platform independent B2C website. Generally include the following aspects:

Taobao Open Platform registered account; through it you can get the application API data call app key and app password. App key app secret Fill in the app key and app secret rebate Website background program, you can apply to Taobao Open Platform. Application approved, you can call Taobao products and stores data in the rebate network. api Rebate network users to copy Taobao commodity URL in the rebate net, search box search rebate networks .The appropriate API interface can be called the display of goods rebate information. pid(process id)id(identity,) This is the way of all Taobao rebates rebate network in cooperation with Taobao.

Your own website can be a key application to apply for the promotion of dozens b2c site CPS. The ad code for each site to promote independent B2C website rebate information can be displayed on the site's front desk. B2ccookie. The user clicks on the promotion link b2c website to buy goods orders, rebates Netcom user cookie tracking orders. B2c In order to promote the commission paid to the promotion, Taobao Alliance monthly closing time, the rebate network need to advance in advance to the user rebates.

Users use social networking account login rebate network. Owned by dozens of independent b2c site cooperation, Taobao can be carried login, when they purchase goods, can be said to serve two purposes. The rebate network Sina microblogging, Tencent, Renren Internet open platform application site access, rebates network users can use their social networks, such as Sina microblogging account login rebate network, eliminating 
the need to re-register the new account trouble . Authorized partner sites account login mechanism, rebate network can improve the conversion rate of the flow and facilitate users to share Goods rebate to their social networks to bring new users to the rebate network.

\section{B. Rebate Network Profit Model}

1) CPS sales dividing. CPS advertising model, cost per sale, to promote consumers click the link and actual commodity trading, businesses paid to the promotion some commissions. A certain percentage of cash back, the rest is the source of income of the rebate network. For example, when user through the rebate network to go Eslite buy a 100 yuan of the shirt, where customers Eslite to rebate network of commission is 16 yuan, and rebate net return to the user 10, that the rest of the 6 yuan is the income of the rebate network.The CPS sales is divided into the total income $=$ each user to buy CPS sales of goods into the accumulation of income, the single items CPS sales into income $=$ amount of users to buy single items * Promotion commission rate * $(1$ - the proportion of cash back - Taobao technical service fee of 10\%). CPS In order to improve the rebate network of CPS sales into income, the key is to find the strong purchasing power of online shopping groups, such as mothers groups.

2) CPM brand advertising revenue. When the rebate network has a larger flow, you can launch CPM Brand Advertising. The shopping rebates Netcom online shopping attract a large number of registered members. They are all online shopping experience, with some spending power. CPM Businesses have certain strength in rebate network. On the one hand, it can increase the influence of the brand; on the other hand, can bring a larger number of potential customers to access the browser. CPM brand advertising is generally in monthly terms, such as the return of the shop link text recommended by the Home stores. The price is 6000 yuan a month. CPM CPM brand advertising in rebate network with more members, businesses will be willing to put in large rebates net income accounted for a large proportion.

3) Joint marketing. In addition to the CPS sales, CPM brand advertising has two profit models. The rebate network has a large number of members and higher user activity; you can also try to joint marketing. The rebate network users, it is mostly women online shopping population, while the free trial to increase interest in their participation in the activity. pba The rebate network users produce a large number of high-quality trial report, to the PBA's new cosmetics brings word of mouth publicity, as listed good thermal field. Brand free trial activities enhance the user in a rebate network of viscosity. At the same time, it gives the user more value addition to the shopping rebates. http://tuan.51fanli.com/ 51Amoy bargain (http://tuan.51fanli.com/ in) 51 rebate networks to operate independently buy part, businesses can sign up for free. Amoy cost-effective to push the main categories: apparel, shoes, bags, household items, office snacks. 51CPS through Amoy cost-effective buy activities, the 51 rebate Network can get the CPS sales commission and enhance user activity, while businesses can get quality traffic and orders for execution.

\section{Rebate Network Trends}

Rebate network has brought practical benefits to the online shopping population. The ultimate goal is operating net purchase home community, the electricity supplier industry upstream enterprises. Changes in several large domestic market share rebate network services, we can predict the future several different trends:

1) Preferential services to provide one-stop shopping for online shopping population. 51 rebate networks is the pioneer of the domestic shopping rebates mode, which set the comparison shopping, coupons, scouring costeffective, Taobao rebates, B2C mall rebate for an integrated rebate platform. Search by parity, the user can get the lowest price of an item outside. Taobao online store will also receive a certain percentage of the rebate. In the coupon section, users can sell their idle, such as where customers Eslite, Amazon and other online store coupons, the official can use the points to redeem coupons. 51 Amoy be cost-effective to buy activity, businesses can sign up for free 51 rebate network to operate independently, where users can buy inexpensive goods. Preferential services provide one-stop shopping for online shopping population rebate platform, eliminating the need for users to use multiple coupons, comparison shopping, online shopping rebate site trouble, an account you can enjoy all shopping discount services.

2) Taobao rebate service has a good user experience .According to CNNIC (China Internet Network Center) in August 2012, produced the "2011 China's online shopping market research report". Taobao's user base is still the highest user penetration rate reached 80.7\%; the second Lynx (Taobao Mall), 54.2\% of the proportion of users [4]. So if the rebate network can concentrate on doing a good job, Taobao rebate services, but also have great potential user base. www.mizhe.com $\mathrm{M}$ fold net (www.mizhe.com) started to focus on Taobao rebates IDG Capital in January 2013, more than \$ 10 million A round of investment. 180\% $\mathrm{M}$ fold net withdrawals of 1 yuan, to invite the Friends Award cash offers convenient Taobao rebate service a large number of users at an early stage. Compared to 51 of 50 yuan rebates network withdrawals, $40 \%$ of the low proportion of the amount of the rebate; $m$ fold net is undoubtedly a better choice. Taobao buyers' rebates of up to 50 yuan in the short term, it is more difficult to achieve. 
3) Provide personalized web shopping guide service. According to Taobao data, each Taobao orders corresponding to the number of PV is in constant growth. 100PVThere are more than 100 PV corresponds to an order; we are difficult to find their favorite products.Rebate network elongated online shoppers shopping process; the size of its subscriber growth is limited [5]. After all, a lot of people find it troublesome back a few dollars. 1000 On the other hand, due to the rebate network of low barriers to entry, the construction of a rebate network required domain name. Rebate program authorized by the total cost of 1000 yuan is enough to cause serious the rebate network of homogenization. A rebate network can provide shopping rebate network of value-added personalized shopping guide services to help the online shopping population faster and better to find their favorite products, which will be more user groups. The Xun shopping network (www.xungou.com) is a social shopping shopping rebate site sharing feature. The user can identify, collect and share your favorite baby, and can use the search rebates. You can get a lot of long tail traffic from the search engines, and attract new users registered members and old user loyalty degree has a certain role.

The rebate network as just shortly development of a new type of online shopping patterns, although there are many defects could be improved. As Master Professor Li Qi, Xi'an Jiaotong University, Department of e-commerce: shopping rebate network, has opened up a new pattern of online shopping, online shopping made comprehensive and innovative. Although in its infancy, facing industry limitations and the development is not perfect. Rebates marketing development prospects will be brighter brilliant.

\section{ACKNOWLEDGMENT}

This research was supported by the funds from: Foundation item 1 : Construction Funds of Master Degree Awarded Unit of Quanzhou Normal University; Foundation item 2: Fujian university key project construction service routines "The port logistics information platform construction, Haqixi prefecture", Project Number: A103; Foundation item 3: Science Plan Project of Quanzhou, Project Number: 2012Z109, 2012Z124; Foundation item 4: Science Plan Project of Fujian "Research of cycle development mode of Fujian agricultural processing industry - Quanzhou for Example".

\section{REFERENCES}

[1] Xin Qing Hong enterprise microblogging marketing value and Strategy [J]. Market Modernization, 2011 (20):46-47. (in Chinese)

[2] Xueming Li microblogging marketing: how to impress consumers [J]. The young reporter ,2011,26:61-62. (in Chinese)

[3] Maureen micro-blog, big impact [J]. Strait Science ,2011,04:53-54 +65 . (in Chinese)

[4] Wang Yubo SME the microblogging marketing analysis [J]. Marketing strategy, 2012 (01):40-41. (in Chinese)

Liu Jie, Zhang $\mathrm{Xi}$, a microblogging marketing incentives [J]. Vitality of enterprises, 2011 (08):38-40. (in Chinese) 